\title{
Revolution of Hope Begun
}

\author{
Taki TAKIZAWA, Shigeo \\ President, NPO International Biophilia Rehabilitation Academy
}

The workshop biophilia 2011 was held in Bucharest, Romania, on September 25, 2011. We got the honorable support from the Japanese Embassy in Romania (Ministry of Foreign Affairs), a Romania embassy in Japan, the Tokyo branch office of the Romania government tourist board for it.

Prof. GELU ONOSE, University of Medicine and Pharmacy "Carol Davila," in Bucharest,

President of the Romanian Society for NeuroRehabilitation (RoSNeRa) affiliated to the World Federation of NeuroRehabilitation (WFNR) - and Member of the WFNR Council, and

President of the Romanian Spinal Cord Society (RoSCoS) affiliated to the International Spinal Cord Society (ISCoS) and the European Spinal Cord Injury Federation (ESCIF), had assumed the position of chairman of it.

The author explained our endeavor of the previous studies and the view of the future on the foundation of the keynote lecture as follows; i) We try to make reader understandable "a possibility of gaining a victory" (possibility of constructing a sustainable super-aged society) and would like to enable it with together. ii) The most intelligible example is the medical treatment of the hemiparesis which is a sequela of apoplexy on the rehabilitation medicine. The patient has been treated on the basis of bending and stretching the contracture hand and/or foot by a physiotherapist with hope to re-acquire activity. iii) Once, a patient who was the detective of the Kanagawa Prefectural Police asked for a female physiotherapist "Please don't be too serious with me." She asked him, "Why." Then he answered, "I had heard that rehabilitation is painful." Once, there had been the questioning to make the crime confess and/or extract a secret from a person by bending and stretching the hand and/or foot over a range of motion. If this is considered, to be sure, it seems to be painful. iv) Moreover, the present condition is that cure those who could be cured and those who could be not cured make it give up. There are more than 1.3 million patients in apoplexy, and half people have given up the sequela.

Some doctors concluded, "An effect is not acquired about the Proprioceptive Neuromuscular Facilitation as a result of reflecting own experience" as introduced in our journal. ${ }^{1)}$ The Kunihiko Fukui MD. Ph.D. who worked as a doctor of the department of rehabilitation for 50 years since 1959 and Tetsuhiko Kimura MD. Ph.D. who was the director of the national rehabilitation center for disabled people announced it with together.

The author claimed so far that restructuring of rehabilitation medicine was required and have driven forward research on it. The author looked back upon the workshop this year and introduced "the revolution of hope begun."

Please read the proceedings shown in the reference for details ${ }^{2}$.

Keywords: sustainable, super-aged society, rehabilitation, painful, sequela, acceptance of disability.

\section{Reference}

1) Kunihiko Fukui, Tetsuhiko Kimura, Shigeo TAKIZAWA, Proposition for the Innovation of the Rehabilitation Medicine - Retrospection and Reflection Related to Mechanism of Proprioceptive Neuromuscular Facilitation,

BIOPHILIA, 2015-1 Pages 53-59, https://doi.org/10.14813/ibra.2015.53

2) Prooc of Workshop BIOPHILIA 2011 in Romania, BIOPHILIA Volume 1, Issue 1

https://www.jstage.jst.go.jp/article/ibra/1/1/1_6/_article/-char/en

Notice and Reference;

This is an abstract of Japanese article of the republished. Full Text (JP) on BRJ (2017-1) p. 95-100

https://doi.org/10.3774/brj.2017.95

It is a re-publication of the Jiji Press Welfare No.5869, p12-15, 27 December 2011. (JP), which was permitted to publish by the editor of the Journal at the time of publication.

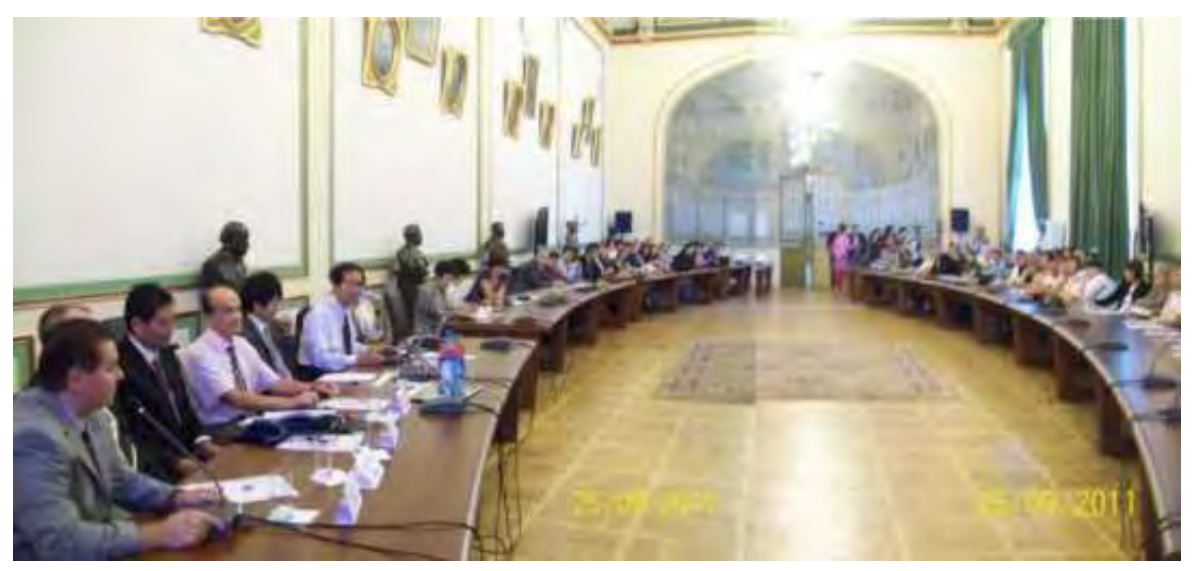

Fig. as Reference 